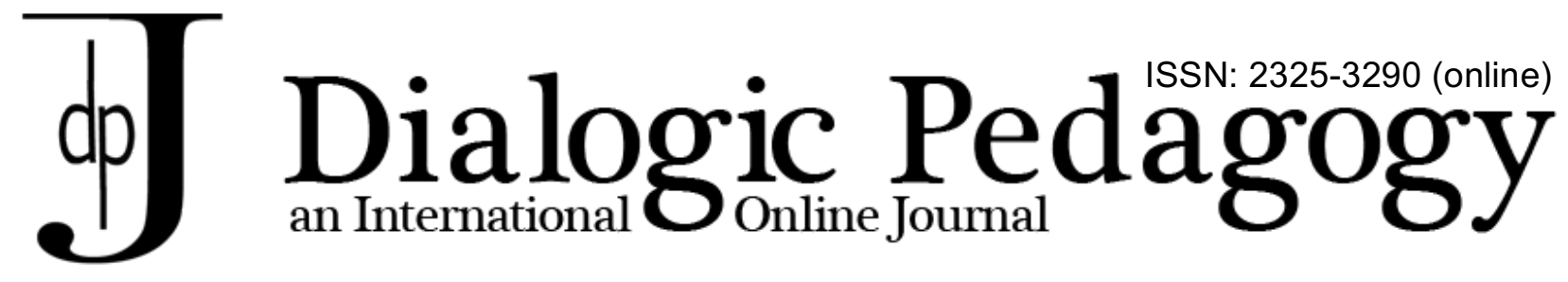

\title{
Between Groys and Gasparov
}

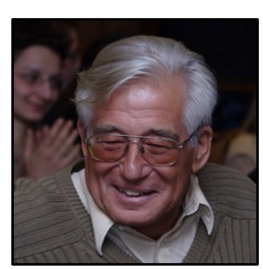

\author{
Alexander Zholkovsky
}

University of Southern California, Los Angeles, USA

Alexander Zholkovsky (b. 1937. Moscow) graduated from MGU (1959), has collaborated with lgor Mel'chuk on structural semantics and with Yurii Shcheglov on structural poetics. Author of over 30 books and almost 400 articles, among them monographs on Boris Pasternak, Isaac Babel and Mikhail Zoshchenko, he is also known for several collections of memoiristic vignettes; his annotated anthology of Russian infinitive poetry is forthcoming from NLO publishers.

\section{$\cos \cos 20$}

There is no need to summarize Boris Groys' article $(1989,1997)$ : it combines laconic richness with exemplary clarity, and is as paradoxical as it is convincing. Just a few words about why I value it so much and how it has influenced me.

The article dates back to 1989, but it was much earlier, during one of Boris's visits to Los Angeles, around 1985, that he privately shared with me its main idea (we had met in Moscow in the 1970s):

"What if, at the time of your [Bakhtinian] carnival, I want to read a book in my ivory tower?!"

With a refreshing shrewdness Groys revealed in his essay the hidden acceptance by Bakhtin of Stalin's totalitarianism-an acceptance that went unrecognized by Bakhtin's Western worshippers, who canonized him as a messiah of pluralistic polyphony. It is noteworthy that by the 1980 s this very canonization of Bakhtin had acquired somewhat totalitarian features. It became practically mandatory to mention Bakhtin in any philological publication. To do so was reliable, practical, and fashionable. On the one hand, I followed that vogue, on the other, I could not wait for the obsession to end.

It came to pass, at long last. In the fall of 2012, I was invited by colleagues at the University of Wisconsin to participate in a conference on Slavic studies as the keynote speaker. Among the speakers were local faculty and $\mathrm{PhD}$ students as well as scholars from other universities. The conference continued for two full days, more than 20 papers were delivered, but it was only at the end of the final panel that I heard Bakhtin's name mentioned. It was something of a shock; it reminded me of the relief I once experienced en route from Zurich to Geneva, when I suddenly realized that the German speech that surrounded me in the train car had been effectively replaced by French (my German is much worse than my French). 


\section{Between Groys and Gasparov}

Alexander Zholkovsky

It does not mean I am absolutely anti-Bakhtin. But there is a time and place for everything.

Let me quote from an old memoiristic vignette. It features the editor of Voprosy Literatury (["The Issues of Literature"], a journal of literary criticism), Sergo Lominadze, who was generally a nice guy but always doggedly followed the ideological demands of the times (we are talking about the 1970s).

On that occasion he limited himself to simply relaying to us the censorship requirements. He demanded we remove the majority of references to Pasternak. My coauthor Yu. K. Shcheglov and I tried to argue that Pasternak was not a proscribed author-he was mentioned in print quite often.

"That's right, replied Sergo, and we have quite unequivocal rules about that. You can quote Pasternak when writing about Pasternak but not when writing about other matters. For such cases you have Marx, Lenin, Gorky, and Belinsky at your disposal."

Our secret "agenda," of course, was to alter the official Soviet pantheon, conferring on the semi-illegal Pasternak the status of a widely-referenced author, but it turned out that the ideological authorities had preempted such Aesopian tricks. Just like Pushkin on having crossed the Arpachay River, we still remained within the borders of immense Russia.

I recalled this episode at a conference on literary theory at Princeton in 2002. A lot was being said about Bakhtin there. His name was bandied around time and again, and, ironically, the monologic length of those presentations exceeded by far the regular time limit. One speaker just kept speaking despite the moderator's insistent gestures and written notes encouraging him to stop. Finally, the speaker said: "Just let me finish one last sentence," but after that he went on and on for a long time, graphically demonstrating thereby the Bakhtinian concept of unfinalizability of discourse and the chasm between a sentence and an utterance [so beloved of Bakhtin]...

In discussing my presentation, Professor Irina Paperno noted that I was the only one at the conference who openly refused to quote Bakhtin. I clarified my point: Bakhtin, in my opinion, should be referenced when speaking about Bakhtin, and perhaps, to a lesser extent, when speaking about carnival or Dostoyevsky. But he should not be quoted as the only authority on all possible subjects-for instance, poetry. Curiously enough, the leading American Bakhtinist, Princeton's Caryl Emerson, mentioned in her presentation a recent article by Sergo Lominadze on the inadequacy of Bakhtin's analysis of [even!] Dostoyevsky, which reminded me of the Pasternak episode (Zholkovsky, 2008).

In the case of Bakhtin, just like in many similar cases, our task is, so to speak, to move the author from the iconostasis, the "icon shelf," back onto the bookshelf proper. This operation becomes especially dramatic-and ironic-when the dethroning concerns an author who was promoted to a position of unlimited power as an apostle of freedom, no less.

It is noteworthy that in his deconstruction of Bakhtin, Groys had an unexpected ally (and to some extent a predecessor) in a representative of a quite different scholarly paradigm-Mikhail L. Gasparov, a specialist in versification as well as classical antiquity, and, what is more striking, a structuralist. Back in 1979, Gasparov published a short essay on Bakhtin, which was as laconic and explosive as the future one by Groys. Five years later it was translated and published in English (Gasparov, 1984). I came across the two debunking essays more or less simultaneously and have been recommending them to my graduate students ever since. 
In his essay, Gasparov moves away from his strict structuralist vow "to never try to read the author's soul" and exposes the deep pragmatic foundations of Bakhtin's position. One of which is his fear of an authoritative culture, first of all, poetry:

If genuine culture is in the future then there is no point clinging emotionally to the culture of the past. In fact, [Bakhtin] had no kindred feeling for either Pushkin, or Shakespeare, or even Tolstoy. He accepted only two things - first, the carnival tradition and Rabelais and, second, Dostoevsky... (It is curious to note with what indifference to the facts he exaggerated the quantity and quality of medieval parodies from other people's accounts and how flippantly he disregarded whole lines in the history of the novel. They were "bad," their authors did not understand what a novel is.) This attitude came about because any harmoniously constructed verbal structure from the cultural past rouses the fear in a new reader: what if it is not I who will master it, but it me?

And hence Bakhtin's ... sharp hostility to poetry, as indeed to "authoritarian language" in general, which dominates the reader too much. We know that poetry, no less skillfully than the novel (and maybe even more skillfully), plays with "someone else's words"; Bakhtin was against poetry not for this reason, but because it is "the language of the gods", exasperating to a person of the new culture, and because poetry is "authoritarian" language which paralyzes the reader's own creativity (Gasparov, 1984, p. 171).

The parallel between the two irreverent subversions of Bakhtin seems obvious. According to Gasparov, Bakhtin is not at all an opponent of the soulless, technocratic Formalists, even though he presents himself as such, but rather their comrade in arms, engaged in the same revolutionary-nihilistic treatment of cultural artefacts-in their selection, appropriation, and demolition.

The feeling "I too can be a bearer of culture" could be experienced in two ways: either "I too can create and not just look up to other creators" (this was like Bakhtin with his cult of active disputatious thinking); or "I too can have an effect on others, not just them on me!" (this was the Formalists with their cult of constructive verbal technology). The hostility between Bakhtin and the Formalists was so obstinate precisely because the struggle was between people of the same cultural formation: the most heated arguments are always over tints, not colors...

The reader who enters into a dialogue with the work can either fit into its context, or fit the work into his own context (dialogue is a struggle: who will give in?). The first alternative is one possibility: Bakhtin acknowledged, though unwillingly, Eikhenbaum's merits for having identified in Tolstoy's works the contexts of his day which everyone else had long since forgotten. But this is tiresome work and, besides, hardly necessary. The second alternative for Bakhtin and for the men of the twenties came much more naturally: not to give in to the thing, but to make it give in, to take from the old world for the construction of the new only what you yourself think is needed and to throw the rest away with contempt. All the culture of the past is merely raw material for the culture of the future (Gasparov, 1984, p. 170).

According to Groys, Bakhtin is not a sly, Aesopian, crypto-opponent of Stalin's totalitarianism, the way he is portrayed by post-modernists, but a sophisticated-I would say, Stockholm-syndrome-styleapostle of the repressive carnival that does not leave any space for freedom (in the sense of autonomy of an individual body and soul). 
In the absolute majority of their works, Bakhtin's "polyphony" is understood as a protest against the "monologism" of Stalin's ideology, of which he was a contemporary, whereas "carnivalization" is understood as a reaction to the impeccably serious and strict tone of the official Soviet institutions of that period. Bakhtin, therefore, becomes a mouthpiece of the democratic, genuinely public alternative to the hierarchically organized totalitarian state - the sole thinker of the Soviet period who remained loyal to the utopian idea of the united, truly "people's" life.

At the same time, Bakhtin insists ... on this totality of carnival... Bakhtin's attitude to liberalism and democracy in their traditional meaning is that of deep antipathy ...

Simply put, Bakhtin's carnival is horrible - God forbid being part of it. There is no place for democracy in it - nobody is given the democratic right to avoid... the carnival, to stay away from it.

The victim of the Apollonian Stalinist terror interprets it as an act of a ritualistic Dionysian self-destruction - and, by that, overcomes this terror, changing its meaning from inside... It should be noted, though, that this overcoming of a life tragedy through self-sacrifice is devoid, in Bakhtin's viewpoint, of that ecstatic dissolution in the unconscious and impersonal, which, for Nietzsche, constitutes the main pathos of the Dionysian. For Bakhtin, individuality is radically limited and final... This "different" totalitarianism cannot be subjected to the usual ideological criticism... because it represents a combination of materialism and the will to self-sacrifice (Groys, 1997).

The crucial feature of the totalitarian carnival, even though it was not explicitly defined as such by Bakhtin, is its centralized organization of power, which only pretends to be chaotic and natural.

The context of Stalin is also supported by the fact that both the polyphonic novel and carnivalesque act, though being allegedly born in the people's mind, are still directed, according to Bakhtin, by a certain super-author - Dostoyevsky or Rabelais, which obliquely points at the author of the corresponding "life text", which could refer to no one else but Stalin (Groys, 1997).

The inherent drama of the ominous, allegedly unpredictable but, in fact, thoroughly organized and controlled performance, so painfully familiar to the subjects of totalitarian regimes, turns out to be a key to many artistic constructions. Thanks to Groys, I was able to recognize and identify this drama in the famous scenes of the exchange of clothes and the subsequent execution of Prince Vladimir in the end of Part II of Sergey Eisenstein's film Ivan the Terrible.

The "Feast of the Oprichniks" segues to the elimination of Vladimir and the entire Boyar threat: detecting the assassination plot, Ivan turns it against its authors. The ready-made mechanism for this pivotal reversal is provided by the carnivalesque hypogram underlying the episode...

The scene proceeds to the archetypal exchange of clothes and other attributes of power between Ivan, the reigning monarch, and Vladimir, the king of fools; then to Ivan grotesquely pretending to humble himself before the new czar; and to the ensuing assassination of the temporary mock-czar instead of the real one.

If this is carnival, it is one with a difference. The real czar never relinquishes his power for a moment, remaining present, sober, and vigilant. The mock-coronation of the fool is initiated and performed by Ivan and his bodyguards, who also provide the crowd of revelers. Vladimir's 
march to his death in the cathedral is performed in what is known in Sovietize as a "voluntaryobligatory manner": the victim is squeezed from all sides by the Oprichniks and pushed in the predetermined direction. This squeezing is effected in full accordance with Eisenstein's recipes for "merciless" geometric compositions...

Both the feast and the killing take place inside a closed space, ... rather than in some Bakhtinian public square, amidst a laughing crowd... The cathedral setting makes Vladimir's death even more of a prearranged sacrifice. The perversely merciless, yet "just", stabbing is performed against the background of Last Judgment frescoes, which directly link Ivan to God... Finally, the 'mock-king' is sacrificed without any prospect of eventual resurrection; thus, instead of leading to or at least symbolizing a renewal, Operation Carnival only reinforces the status quo.

The net result is a carnival stage-managed by one of the parties: the authoritarian parental side. It is conceived, provoked, put on, and firmly controlled from above, so that all its contradictions, role-reversals, playfulness, intoxication, and irrational energy are pressed into the service of the tyrannical Father directing it.

All this makes the ties between Eisenstein's esthetic theory-and-practice and Ivan's directorial activities suspiciously similar: Eisenstein's terrible protagonist turns out to be his double... but it is not easy to recognize Eisenstein in the merciless old Ivan of the second part...

Spectacles - theater, circus, street festivals, etc. - were prominent in the system of artistic genres fostered by the Avant-garde after the Revolution. They were inherited and transformed by Stalinist culture into staged mass demonstrations, Soviet-style elections, political show trials, Stakhanovite feats of productivity, and carnivalesque role-reversal campaigns (e.g., harvest trips, with intellectuals performing manual work under the guidance of peasants). Theater naturally became the Art par excellence as Stalin assumed the role of the supreme Director of the totality of Soviet life (Zholkovsky, 1996).

A similar appropriation of carnival, although in milder form, was practiced by Anna Akhmatova, the master of life-as-art power play. The mock recital ("à la Vertinsky") of her poems by Alexey Batalov, initiated and choreographed by Akhmatova herself and attended by Vertinsky, Akhmatova, and a number of chosen guests in the Ardovs' apartment on Ordynka Street [in Moscow], had as its aim to downplay and erase the unpleasant memories of the public parodying of her "Grey-Eyed King" by Mayakovski. In other cases, similar performances were played out at Akhmatova's request by Faina Ranevskaya.

Let's take a closer look at the hidden psychological dynamics of these performances... It is true that their carnivalesque humor was aimed at Akhmatova herself and served to downplay the atmosphere of her greatness. However, it was not an unexpected, independent laughter from outside, which would threaten to undermine her greatness, as was the case with Mayakovski's public mockery of her poems. On the contrary, Akhmatova herself was the initiator and the "director" of the "insults". Having meticulously reconstructed all the details of the past situation that was troubling for her - the shocking performance of her poems to an incongruous tune, humiliating familiarity, the inversion of gender roles, collective laughter, - she added one new and very important aspect - her complete personal control over the event...

It cannot but remind one... of the "regally" directed carnival in Eisenstein's Ivan the Terrible and of its real historical prototype: Stalin's cruel humor at the expense of the victims of his carnivalized repressions...

Such usurpation of carnival doubtlessly attests to the power of its organizers - yet, not in the sense of their bold openness to the free play of laughter - but in the sense of controlling and manipulating laughter within a carefully fenced off enclosure of their "own" territory... As for humor 
itself, it irresistibly mutates under such pressure of power. In case of success, it adopts a conceited or ominous, "barbaric", air - and if it fails, it ends up being redirected against the "tyrant" (Zholkovsky, 2005, pp. 227-229).

Akhmatova, Eisenstein, and Bakhtin all bear marks of the oppressive atmosphere of the 1930s, which is further proof that all phenomena should be analyzed within their historical context. It is precisely such contextualization that both Groys and Gasparov bring to their reading of Bakhtin.

...Bakhtin's aim was not to criticize the Revolution and Stalin's terror from a democratic standpoint, but to theoretically justify them as an eternal carnivalesque act... Contemporary researchers of Bakhtin mostly think in the pre-revolution paradigm, whereas Bakhtin himself was a post-revolution thinker... (Groys, 1997).

Mikhail Bakhtin systematized his ideas on language and literature in the $1920 \mathrm{~s}$, but it was not until the 1960s that they became generally known and the subject of wide discussion. Every age has its "struggle of the ancients and the moderns," and in the present round of the struggle Bakhtin's works and utterances have become an important weapon... Bakhtin is made into the bearer of the lofty spiritual values of the past, the organic integrity of which is threatened by the soulless analytical methods of today. There are good reasons for such a view, though not much foundation for it. For this view leaves out too much in the logical coherence of Bakhtin's ideas. What exactly it leaves out will become clear if we recall the period in which Bakhtin's ideas were formed (Gasparov, 1984, p. 169).

The irony of Bakhtin's fate was that he thought in dialogue with the twenties, but was published, read and respected at a time when his colleagues had already left the scene and strangers had gathered around him. The prophet of the new renaissance became canonized by the age of the new classicism. The overthrower of every kind of piety has himself become the object of piety. His followers have come too late and made a research theory out of his program for creativity. And these are things which are in principle opposed: the point of creation is to transform an object, whereas the point of research is not to deform it. ... [A]s Bakhtin called on his contemporaries to take from the culture of the past only what they thought necessary for themselves, so now his new adherents take from his writings only what they think is necessary for them. But it is always best when this is done consciously... To use Bakhtin's provocatively imprecise language we might say: Bakhtin's work is a novel, don't make it into an epic (Gasparov, 1984, p. 172).

As usual, we can only hope that history will eventually set the record straight and, as the poet Joseph Brodsky said, life "can sway aright, once swayed aleft."

\section{References}

Gasparov, M.L. (1984). M.M. Bakhtin in Russian culture of the Twentieth Century. Transl. and comm. by Ann Shukman. Studies in 20th Century Literature, 9. 169-176. (http://newprairiepress.org/sttcl/vol9/iss1/12)

Groys, B. (1997). Totalitarianism of Carnival (in the current issue)???.

Zholkovsky, A. (1996). Eisenstein's Poetics: Dialogical or Totalitarian? Laboratory of Dreams: The Russian Avant-Garde and Cultural Experiment (Ed. by John E. Bowlt and Olga Matich). Stanford University Press, 1996: 245-256. (http://www-bcf.usc.edu/ alik/eng/ess/eis.htm) 


\section{Between Groys and Gasparov}

Alexander Zholkovsky

Zholkovsky, А. (2005). Ахматова и Маяаковский. К теории пародии [Akhmatova and Mayakovski. On the theory of parody]. In A. Zholkovsky. The selected articles on Russian poetry. Invariants, structures, strategies, intertextuality. Moscow, 2005, pp. 221-231 (https://dornsife.usc.edu/alexander-zholkovsky/am/)

Zholkovsky, A. (2008). The clashes of authorities. In A. Zholkovsky. Stars and slightly nervous. Memoir vignettes. Moscow: Time, 2008, pp. 132-134. (http://wwwbcf.usc.edu/ alik/rus/book/zvez/zv64.htm).

\section{(cc) EY}

New articles in this journal are licensed under a Creative Commons Attribution 4.0 United States License.
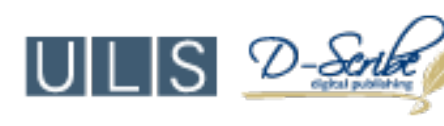

This journal is published by the University Library System, University of Pittsburgh as part of its D-Scribe Digital Publishing Program and is cosponsored by the University of Pittsburgh Press. 